\title{
THE FIXATION OF A PROXIMAL TIBIAL POLYETHYLENE PROSTHESIS WITHOUT CEMENT
}

\author{
J. D. BLAHA, H. P. INSLER, M. A. R. FREEMAN, P. A. REVELL, R. C. TODD \\ From the London Hospital and the London Hospital Medical College, London
}

\begin{abstract}
A polyethylene prosthesis has been developed which can be fixed without cement as the tibial component of a knee replacement. This prosthesis has been used both with and without cement in a series of 144 arthroplasties of the knee. The results of clinical and radiographic follow-up for one to four years are presented, together with some histological material. This cementless method of fixation is satisfactory at the site tested and for the period of the follow-up.
\end{abstract}

The introduction of polymethylmethacrylate cement as a method of implant fixation by Charnley in 1958 started the modern era of joint replacement surgery. Clinical experience has shown that a prosthesis bonded to bone with "cement" will be painless unless the implant mass moves against the bone under load. Fixation is seen to be necessary for clinical success, but it is uncertain that cement is necessary to secure fixation.

Loosening may be due to two, often co-existing, causes. The prosthesis may sink or migrate into the bone as a result of crushing due to compressive forces, or the implant may be displaced away from the bone by tensile or shear forces at the interface. Loosening will obviously be affected by the design of the prosthesis, the surgical technique used and by the local strength of the bone, whether or not cement is employed. The use of cement may reduce loosening by filling the spaces between the bone and the implant so that the contact area is increased and the compressive stresses are reduced. Cement can also be made to flow into recesses in bone either on a gross scale into cysts or surgical irregularities, or on a smaller scale into the intertrabecular spaces of cancellous bone to produce an interlock capable of resisting tension and shear.

The bone at a cement interface usually, and perhaps always, dies for depth of a few cells from the cement surface (Willert, Ludwig and Semlitsch 1974). Remodelling then leaves a soft-tissue interface, which suggests that a permanent small-scale interlock capable of resisting tension and shear may rarely, if ever, be achieved. It is possible that techniques of injecting cement into cancellous bone may produce a different kind of interface. The soft tissue covering cancellous bone such as that of the acetabulum is cartilage-like where the interface may be load-bearing and fibrous where there is no load (Charnley and Crawford 1968; Charnley 1979).

The lining cell in the fibrous soft tissue is often a resting macrophage (Charnley 1979) and the macrophage is the precursor of the osteoclast (Chambers 1980). The interface thus includes cells which are capable of destroying bone, and must be regarded as biologically unstable; to quote Charnley himself (Charnley 1979) "Histiocytes (macrophages) and foreign-body giant cells represent a tissue reaction which no implant surgeon can lightly dismiss".

Polymethylmethacrylate cement has other disadvantages. Its use prolongs the operation. It is abrasive and brittle, and is weak in tension and in shear (Swanson 1977). There is also an unproven but distinct impression that its presence may allow usually non-pathogenic organisms to cause clinically significant osteitis (Charnley, Follacci and Hammond 1968; Petty et al. 1975; Feith et al. 1976; Petty 1978; Chenger et al. 1981). In view of these considerations, a method has been developed of bonding an implant to bone without the use of cement. A polyethylene component was chosen because its radiolucency allowed bone "within" the implant to be radiographed and because living, unloaded canine bone remains healthy and will grow into polyethylene with which it is in contact (Sauer et al. 1974; Sauer, Lade and Mercer 1980, 1981). The tibial component of a knee

J. D. Blaha, MD, Lecturer in Orthopaedic Surgery

University of West Virginia, Medical Center, Morgantown, West Virginia 26506, USA.

H. P. Insler, MD, Lecturer in Orthopaedic Surgery

The Bronx Lebanon Hospital Center, 1650 Grand Concourse, Bronx, New York 10457, USA

M. A. R. Freeman, MD, FRCS, Consultant Orthopaedic Surgeon

P. A. Revell, PhD, MRCPath, Consultant Pathologist

R. C. Todd, FRCS, Honorary Consultant Orthopaedic Surgeon

Bone and Joint Research Unit, The London Hospital Medical College, Arthritis and Rheumatism Council Building, 25-29 Ashfield Street, London EI 2AD, England.

Requests for reprints should be sent to Mr M. A. R. Freeman.

(C) 1982 British Editorial Society of Bone and Joint Surgery 0301-620X/82/3067-0326 \$2.00 
replacement was chosen as a test site since this is one in which secure fixation has been difficult to achieve (Bargren et al. 1976; Insall et al. 1976; Skolnick et al. 1976; Skolnick, Coventry and Illstrup 1976; Freeman et al. 1978; Goldberg and Henderson 1980) and a new technique would be significantly tested. It is also a site where the absence of thick soft tissue makes high quality radiography possible.

This paper presents the basic principles of a method of cementless fixation and reports clinical, radiographic and histological findings in knee replacements using this method of fixation.

\section{IMPLANT DESIGN}

Bargren et al. (1978) showed experimentally that adequate resistance to compression could be achieved if the proximal surface of the tibia were to be replaced by a cemented flat sheet of polyethylene large enough to rest on the whole cut surface, including the cortices. Clinical experience in 1975 and 1976 with such an implant (the ICLH tibial component) confirmed that it did not sink into the tibia during a short-term follow-up (Freeman $e t$ al. 1978).

The use of a flat-bottomed implant without cement necessitates making the cut tibial surface as flat as possible in order to provide an adequate area of contact for the transmission of the load. A power saw (the Tuke saw) was invented which could cut cancellous bone with great accuracy. A flat sheet of glass was used on the cut surface so that high points could be seen and later trimmed.

The undersurface of the implant had two pegs to lock the prosthesis to strong cancellous bone in the upper tibia (Bargren et al. 1978; Freeman et al. 1981). These pegs could resist rotation in all three planes and shear forces in the plane of the base of the implant. Two holes were drilled into the tibia to receive the pegs. A template

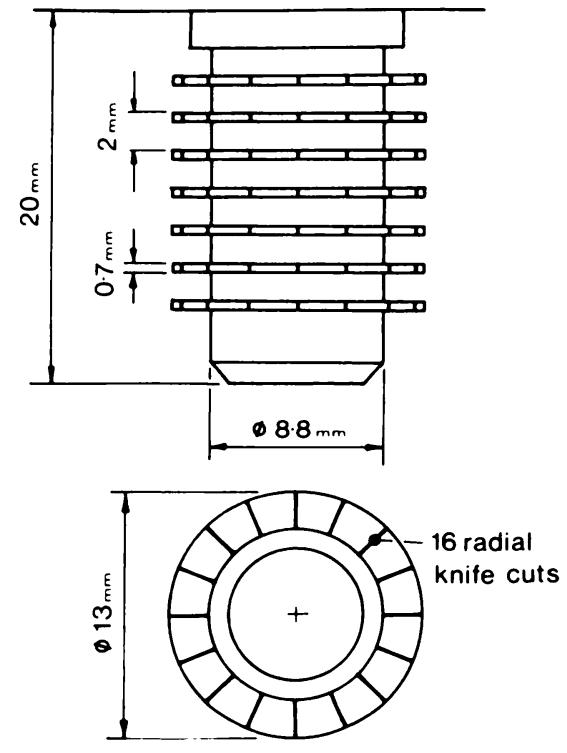

Fig. 2 and a drill guide were used to ensure that the holes were precisely vertical, of precisely the right depth and correctly spaced. A drill with a limited flute was used so that cancellous bone chips produced by the drill were packed into the cancellous walls of the drill holes.

A design study (Freeman et al. 1981) determined the optimal size of the peg and developed a surface contour for the pegs such as would interlock with bone at the moment of implantation and provide immediate resistance to withdrawal comparable with that of an AO cancellous bone screw. The final appearance of the implant and its pegs are seen in Figures 1 and 2. A series of polyethylene flanges project from the circumference of the peg. It was established by experiments on cadavers (Bargren et al. 1978; Freeman et al. 1981) that when such a peg was driven into a hole in cancellous bone intermediate in diameter between the core of the peg and the outer edge of the flanges, the flanges would flex as they entered the bone. They then either sprang out into an intertrabecular space or remained flexed tightly against intact trabeculae, depending on the local anatomy (Fig. 3). In clinical practice, it was hoped that flanges in

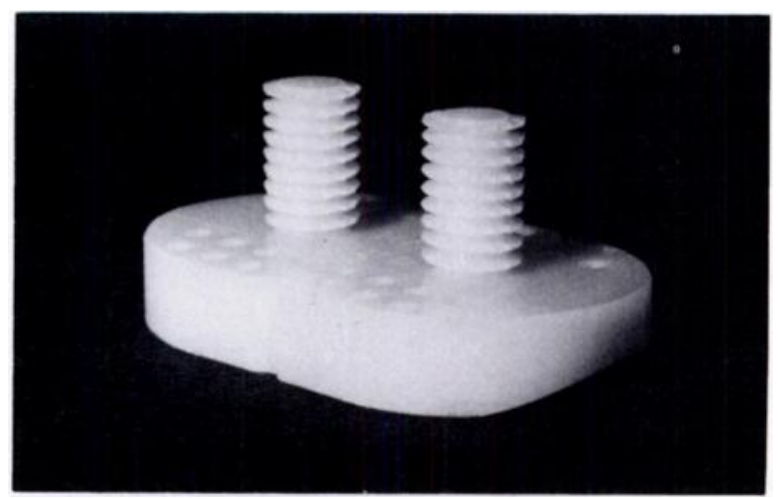

Fig. 1

The prosthesis, showing the two flanged pegs integral with the plateau of the implant.

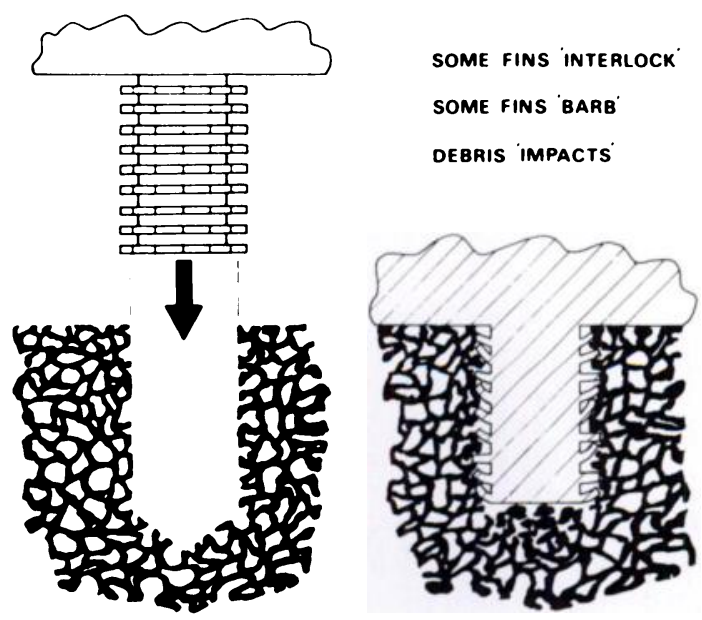

Fig. 3

Diagrams of the flanged peg. Figure 2-The flanges are split at each level so that there are a series of separate radially arranged projections. Figure 3-Diagram to show the way in which the flanges are thought to engage cancellous bone. 
the first position would interlock with living, intact trabeculae whilst in the latter position they would resist extraction by acting as barbs. It was thought that the bone chips generated by the drill would act as minute bone grafts and enhance the interlock between polyethylene and bone when they became incorporated.

\section{METHODS AND MATERIAL}

This new method of cementless fixation was assessed clinically in a study in which the same prosthesis (the ICLH prosthesis for total replacement of the knee) was used for a three-year period both with and without the use of cement to fix the tibial component. The patients were reviewed at the end of 1980 to provide a direct clinical comparison between groups of knees differing only with respect to the method of tibial fixation. A radiographic review of these patients was carried out in order to study the interface between polyethylene and bone.

Implantation of the ICLH knee prosthesis using the tibial component shown in Figure 1 began in January 1977. Between that date and December 1979, 144 prostheses were implanted as primary arthroplasties either by the senior author (MARF) or under his direct supervision. One hundred and sixteen of these form the material for this study. The grounds for exclusion from review are shown in Table I, and the sex, age, previous the prosthesis were simply driven into the drill holes in the tibia until the plateau of the prosthesis rested on bone. When the tibial component was fixed with cement, PMMA cement was placed on the top of the tibia and in the drill holes. The pegs were then driven in, expressing cement into the intertrabecular spaces in the surrounding bone and compressing the cement beneath the plateau of the prosthesis. The prosthesis and the preparation of the bone itself were exactly the same in the two groups.

In a number of knees allocated to cementless fixation the level of section of the proximal tibia passed above the floor of a defect in the tibia. In the absence of cement the prosthesis covering this defect would have been unsupported and thus incapable of transmitting load. Such defects were therefore filled with cement. Occasionally such a defect overlapped a drill hole, and in such cases the peg was surrounded with cement.

Three groups were defined according to the method of fixation of the tibial component. In Group 1 no tibial defect was present and the interface was entirely between polyethylene and bone. In Group 2 a defect was present in the tibia and was filled with cement. Both polyethylene and cement had interfaces with bone. In Group 3, whether or not a defect had been present, the interface with bone was PMMA cement.

In all patients the femoral component was fixed with cement. The posterior surface of the patella was either

Table I. Number of knees included in, and excluded from the clinical review

\begin{tabular}{|c|c|c|c|c|}
\hline $\begin{array}{c}\text { State of the knee at } \\
\text { review }\end{array}$ & Group 1 & Group 2 & Group 3 & Total \\
\hline $\begin{array}{l}\text { Included in review } \\
\text { Excluded from review: }\end{array}$ & 52 & 33 & 31 & 116 \\
\hline Tibial loosening & - & 2 & 1 & 3 \\
\hline Patella subluxation & 2 & 2 & - & 4 \\
\hline Infection & $\begin{array}{c}5 \\
\text { (all RA) }\end{array}$ & $\left(\begin{array}{c}1 \\
(O A)\end{array}\right.$ & - & 6 \\
\hline $\begin{array}{l}\text { Death } \\
\text { - before } 6 \text { months } \\
\text { - after } 6 \text { months }\end{array}$ & $\begin{array}{l}4 \\
1\end{array}$ & $\overline{1}$ & - & $\begin{array}{l}4 \\
2\end{array}$ \\
\hline $\begin{array}{l}\text { Medically disabled } \\
\text { (CVA, Parkinson`s } \\
\text { disease, depression) }\end{array}$ & $\begin{array}{c}4 \\
\text { (3 patients) }\end{array}$ & - & - & 4 \\
\hline \multirow{2}{*}{$\begin{array}{l}\text { Inadequate follow- } \\
\text { up }\end{array}$} & 2 & 2 & 1 & 5 \\
\hline & 70 & 41 & 33 & 144 \\
\hline
\end{tabular}

operations, diagnosis and duration of follow-up of the 116 knees are shown in Tables II to VI. The four knees excluded from clinical review because of patellar subluxation were included in the radiographic review.

Before operation each knee was allocated in random fashion to one of two methods of tibial fixation: without or with cement. In the group without cement, the pegs of resected or replaced by a prosthesis which could be fixed with or without cement. The management of the patella was varied in random fashion over all three groups. During the early part of the series a technique of realignment of the patella had not been developed and a number of patients suffered lateral subluxation of the patella. 
Table II. Sex of patients included in the three groups

\begin{tabular}{|l|c|c|c|}
\hline \multirow{2}{*}{\multicolumn{1}{|c|}{ Sex }} & \multicolumn{3}{|c|}{ Group } \\
\cline { 2 - 4 } & 1 & 2 & 3 \\
\hline Male & 11 & 11 & 8 \\
Female & 41 & 22 & 23 \\
\hline Total & 52 & 33 & 31 \\
\hline
\end{tabular}

Table III. Age in years of the patients at the time of operation

\begin{tabular}{|c|r|r|r|}
\hline \multirow{2}{*}{$\begin{array}{c}\text { Age } \\
\text { (years) }\end{array}$} & \multicolumn{3}{|c|}{ Group } \\
\cline { 2 - 4 }$<<40$ & 2 & 2 & 3 \\
\hline $41-50$ & 5 & 3 & 5 \\
$51-60$ & 20 & 12 & 6 \\
$61-70$ & 14 & 13 & 10 \\
$>70$ & 11 & 5 & 6 \\
\hline Total & 52 & 33 & 31 \\
\hline
\end{tabular}

Table IV. History of previous operations in all patients

\begin{tabular}{|l|r|c|c|}
\hline \multirow{2}{*}{ Operation } & \multicolumn{3}{c|}{ Group } \\
\cline { 2 - 4 } & $\mathbf{1}$ & $\mathbf{2}$ & $\mathbf{3}$ \\
\hline Osteotomy: & 3 & 0 & 2 \\
Tibial & 2 & 0 & 1 \\
Benjamin & 0 & 0 & 2 \\
MacIntosh arthroscopy & 0 & 1 & 0 \\
Patellectomy & 2 & 2 & 5 \\
Synovectomy & 4 & 4 & 1 \\
Meniscectomy & 1 & 0 & 1 \\
Other & 12 & 7 & 12 \\
\hline Total & & & \\
\hline
\end{tabular}

Clinical and radiological assessment. Patients were examined before operation, after operation and at six months, one year and annually thereafter. History and physical signs were recorded on standard data sheets and analysis was aided by a computer. Pain, the ability to walk and the range of movement were chosen to compare the clinical results in the three groups.

Radiographs were obtained before operation in anteroposterior, lateral, "skyline" and standing long-leg views. These radiographs were repeated three weeks after operation and at each subsequent examination. Macrograms were taken in some cases.

The plateau of the prosthesis and the bone subjacent to it were visible on standard anteroposterior and lateral radiographs. Loosening of the prosthesis resulting in elevation of the component from the bone was obvious
Table V. Diagnosis before operation

\begin{tabular}{|l|c|c|c|}
\hline \multirow{2}{*}{\multicolumn{1}{|c|}{ Diagnosis }} & \multicolumn{3}{|c|}{ Group } \\
\cline { 2 - 4 } & 1 & 2 & 3 \\
\hline Osteoarthritis & 20 & 16 & 9 \\
$\begin{array}{l}\text { Inflammatory arthritis } \\
\text { (usually rheumatoid } \\
\text { arthritis) }\end{array}$ & 27 & 17 & 20 \\
$\begin{array}{l}\text { Post-traumatic } \\
\text { osteoarthritis }\end{array}$ & 4 & 0 & 0 \\
Other & 1 & 0 & 2 \\
\hline Total & 52 & 33 & 31 \\
\hline
\end{tabular}

Table VI. Length of follow-up after operation

\begin{tabular}{|c|c|c|c|c|c|c|}
\hline \multirow{2}{*}{$\begin{array}{c}\text { Interval in } \\
\text { years }\end{array}$} & \multicolumn{5}{|c|}{ Knees reviewed } \\
\cline { 2 - 7 } & Group 1 & \multicolumn{2}{|c|}{ Group 2 } & \multicolumn{2}{c|}{ Group 3 } \\
\cline { 2 - 7 } & Number & Per cent & Number & Per cent & Number & Per cent \\
\hline 1 & 18 & 34 & 14 & 42.5 & 12 & 39 \\
2 & 20 & 39 & 14 & 42.5 & 15 & 49 \\
3 & 13 & 25 & 5 & 15 & 3 & 9 \\
4 & 1 & 2 & 0 & 0 & 1 & 3 \\
\hline Total & 52 & & 33 & & 31 & \\
\hline
\end{tabular}

and bone which might have grown into the holes in the underside of the prosthesis would have been visible. Sinking of the prosthesis was less easy to detect but was sought by measuring the angle of the tibial component relative to the axis of the proximal one-third of the tibia in the initial and the latest anteroposterior and lateral radiographs.

To determine the observer error of this measurement, 30 films were measured twice at different sittings by the same examiner. The difference in measurement and the mean and standard deviation of the difference were calculated. This showed that angles greater than three degrees were likely to be significant. This angle corresponds to four millimetres of vertical movement of one side of the 80-millimetre tibial component. Apparent changes in the angle could be produced by changes in $x$-ray projection at different examinations. Therefore, if the measured angle appeared to change by three degrees or more, confirmation of possible tilt was sought by measuring the distance between points on the prosthesis and on the skeleton. This could be done to an accuracy of approximately two millimetres. These two methods of measurement could thus detect angular tilt of three degrees or sinkage of two millimetres. Lesser displacements could not be detected with certainty.

The radiodensity and distribution of bone near the prosthesis were assessed separately for the zone under the horizontal part of the prosthesis and around each peg. The appearances around the pegs were graded 

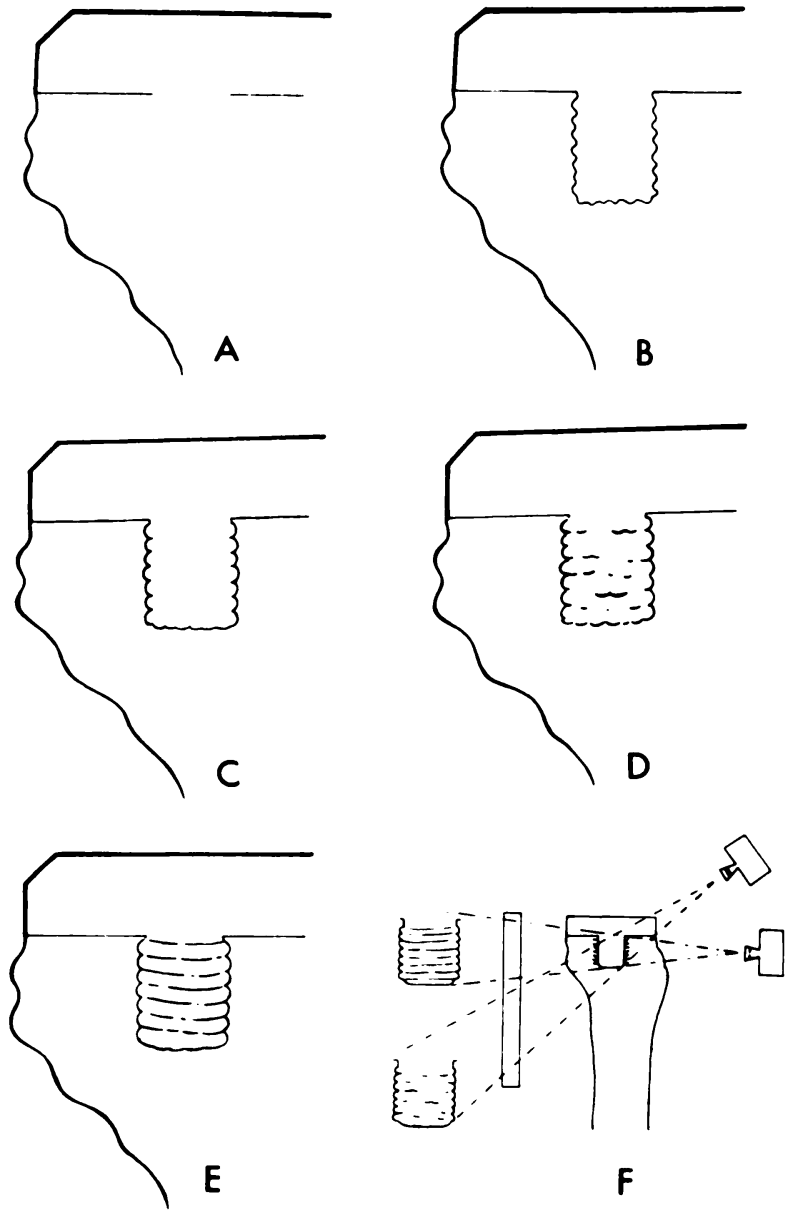

Fig. 4

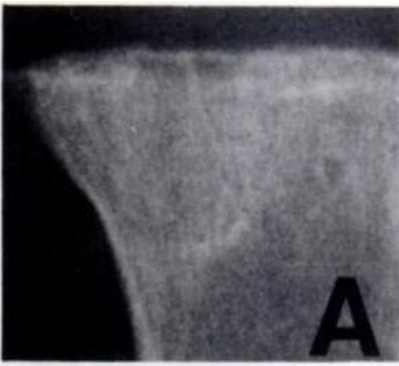

Fig. 5

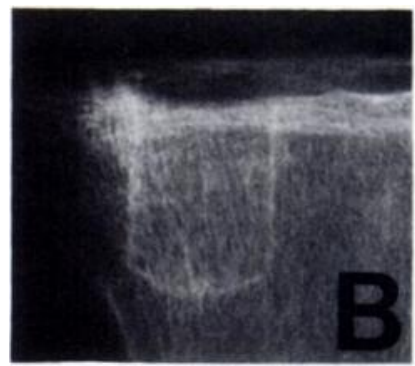

Fig. 6

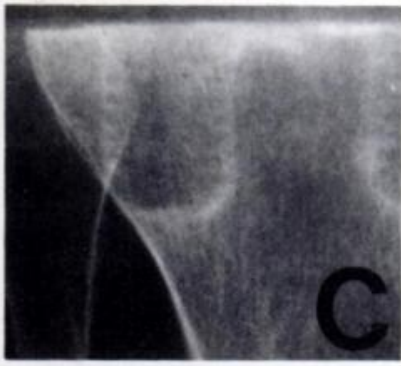

Fig. 7

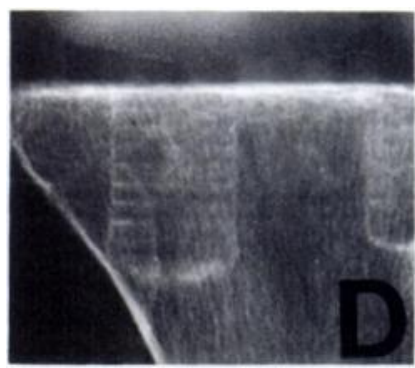

Fig. 8

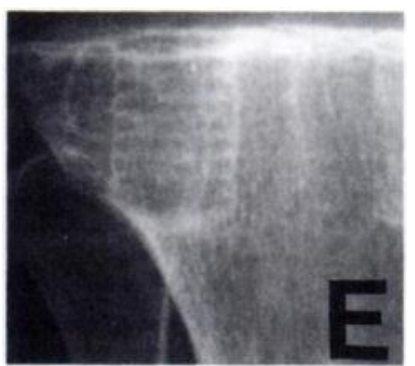

Fig. 9

Figure 4-Line diagrams of the radiological characteristics by which the pegs were graded from $A$ to $E$ and diagram $F$ to show that obliquity of the $x$-ray beam relative to the axis of the peg may produce falsely low grading. Figures 5 to 9 -Representative examples of the graded radiological appearances of pegs taken at least one year after operation and graded respectively A to E. The frequency with which each grade was seen is shown in Table VIII.

according to the appearances illustrated in Figures 4 to 9. Changes in bone density proved difficult to assess because of variation in radiographic techniques. Test films on several patients showed that the apparent density of the bone of the plateau was markedly dependent upon the angle of the incident $x$-ray beam and that the appearance about the pegs and their flanges could be varied by one to two grades by variation in the angle and the power of the beam (Fig. 4). This variation, however, could only have reduced the apparent grade as compared with its real grade. The variations in technique may result in failure to demonstrate bone that was in fact present around the peg, but could hardly have shown bone which was not present. For this reason, it is probable that the grades recorded in the results should be regarded as minimal.

\section{RESULTS}

The three groups were similar with respect to sex, age, previous surgery, diagnosis and duration of follow-up (Tables II to VI respectively).

Clinical review. The results with respect to pain, ability to walk and range of movement are summarised in Table VII. There was no significant difference between the three groups in respect of any of these indices. Patients whose prostheses were fixed without cement were clinically indistinguishable from those whose prostheses were fixed with cement.

Radiographic review. No prosthesis fixed without cement was found to be loose. One fully cemented prosthesis loosened and tilted more than three degrees. This patient had rheumatoid arthritis and extreme osteoporosis with severe damage to the other knee and both hips.

No prosthesis sank in Group 1 or in Group 3. Two prostheses sank on the side of a cemented defect in Group 2. In one of these patients there was a preoperative varus deformity of 35 degrees combined with a varus curve in the tibia itself. At operation the varus deformity in the knee was corrected but the varus in the tibia was accepted. As a result, the mechanical axis of the leg was not restored to normal and medial overload of the tibial plateau caused sinking of the medial side of the prosthesis at two years.

The symptoms are not so severe as to indicate a 
Table VII. Function at review recorded as the number and percentage of each group presenting with pain, reduced ability to walk, or reduced range of movement

\begin{tabular}{|c|c|c|c|c|c|c|c|c|}
\hline & \multicolumn{2}{|c|}{ Group $1(n=52)$} & \multicolumn{2}{|c|}{ Group $2(n=33)$} & \multicolumn{2}{|c|}{ Group $3(n=31)$} & \multicolumn{2}{|c|}{$\begin{array}{c}\text { All three } \\
\text { groups }(n=116)\end{array}$} \\
\hline & Number & Per cent & Number & Per cent & Number & Per cent & Number & Per cent \\
\hline Pain requiring analgesia & 2 & 4 & 3 & 9 & 2 & 6 & 7 & 6 \\
\hline $\begin{array}{l}\text { Inability to walk for } 30 \\
\text { minutes }\end{array}$ & 23 & 44 & 11 & 33 & 14 & 45 & 48 & 41 \\
\hline $\begin{array}{l}\text { Range of movement less } \\
\text { than } 90 \text { degrees }\end{array}$ & 9 & 19 & 9 & 30 & 5 & 16 & 23 & 21 \\
\hline
\end{tabular}

revision operation. The second patient had previously had a synovectomy through a lateral parapatellar incision. This was reopened for the arthroplasty. Before operation the knee showed a five degree varus deformity with a medial tibial defect. The reconstruction of the tibiofemoral joint was satisfactory but the patella was then found to track laterally. It was decided to accept this malalignment rather than to leave the lateral retinaculum open as a release procedure. The popliteus tendon was not released. One year later the patella had dislocated laterally with tibial displacement so that load was transmitted only through the medial half of the tibial plateau. The tibial prosthesis sank on its medial side as a consequence.

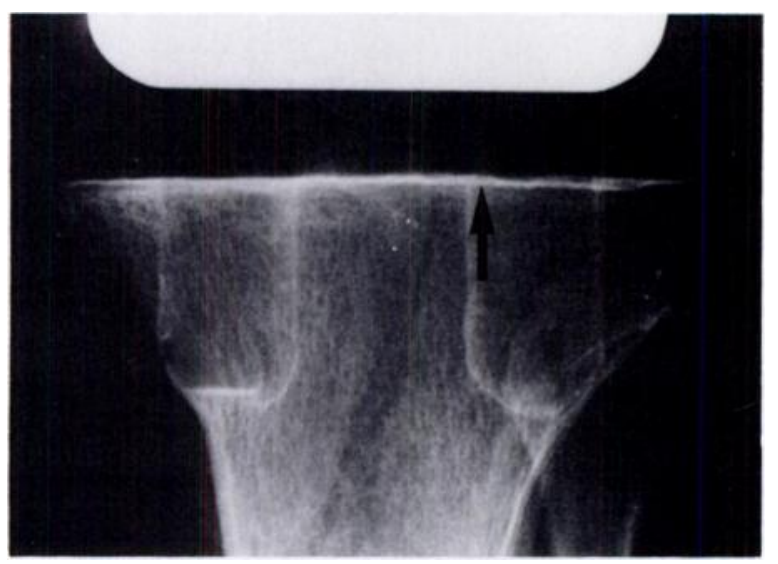

Fig. 10

Radiograph to show probable bone growth into the holes in the undersurface of the prosthesis. This appearance was seen in only two knees.

Appearances interpreted as bone growth into the holes in the undersurface of the prosthesis were seen only in two knees in Groups 1 and 2 (Fig. 10). Six implants had been made in the laboratory with no holes in the undersurface, and these could not have allowed ingrowth of bone.

The radiodensity of the bone in contact with the undersurface of the horizontal uncemented portion of the prostheses in Groups 1 and 2 was never seen to decrease. The bone did not change in density in 56 per cent and in 44 per cent density appeared to increase

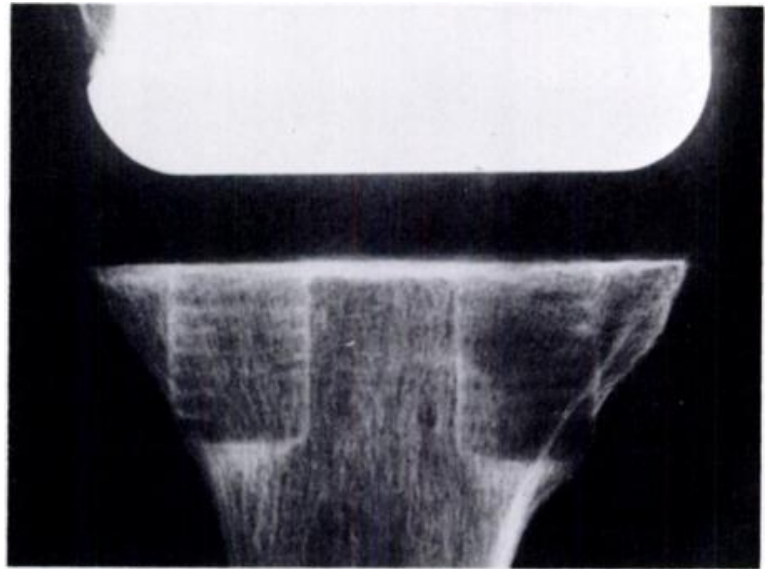

Fig. 11

Radiograph taken three years after operation to show the presence of a thin line of dense bone immediately beneath the tibial plateau. Subperiosteal new bone has formed around one peg, which was inserted after penetration of the cortex by the drill.

forming a pencil-thin straight line of dense bone immediately below the prosthesis (Fig. 11).

The grade of bone density and appearance around each uncemented peg in Groups 1 and 2 in the most recent follow-up film according to the criteria shown in Figures 4 to 9 is recorded in Table VIII. The areas around

Table VIII. Radiological appearance of the
pegs at the last review (Groups pegs at the

\begin{tabular}{|c|c|}
\hline Grade & Incidence (per cent) \\
\hline A & 0 \\
B & 36 \\
C & 31 \\
D & 29 \\
E & 4 \\
\hline Total & 100 \\
\hline
\end{tabular}

The grading system is shown in Figures 4 to 9

all pegs had a radiodensity of at least Grade B on the most recent follow-up film. Radiodensity about the pegs showed an apparent decrease after operation of one grade in 3.3 per cent of pegs. There was no change in 40.4 


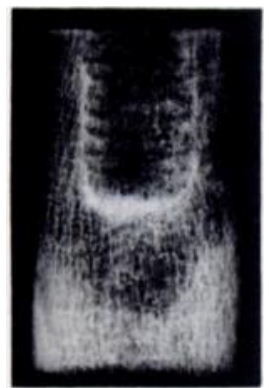

Figure 12-Radiological appearance of a block of bone containing a peg which was removed from the tibia of a patient who died four weeks after operation. Figure 13Photograph of a sagittal section of the tibia, with an uncemented prosthesis from a patient who died three weeks after operation.

Fig. 12

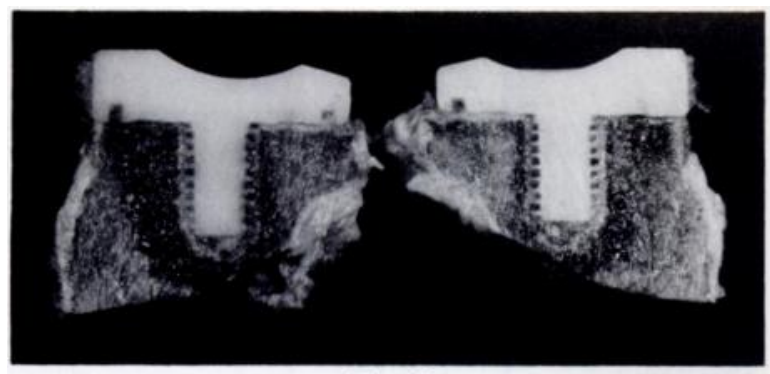

Fig. 13

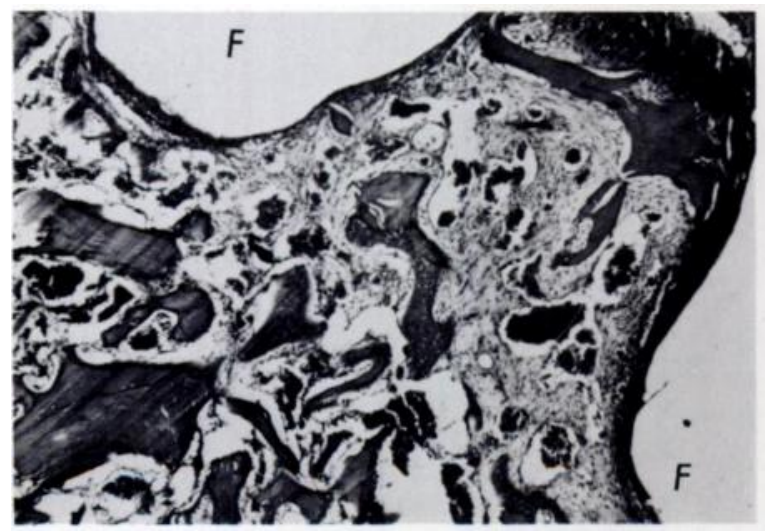

Fig. 14

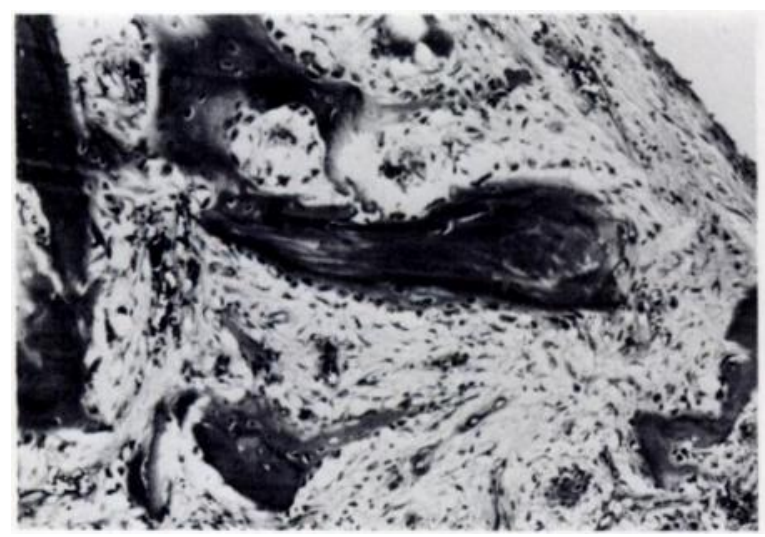

Fig. 16 per cent and an increase of one or two grades around 56.3 per cent of the pegs. The two pegs in any one knee were frequently not in the same grade but were usually within two grades of each other. No relationship was observed between the medial or lateral side of the peg and the grade. The pegs were not graded on their appearance in a lateral projection because this caused superimposition, but the apparent grade in the lateral view often seemed to be higher than that assessed in an anteroposterior view. When the drill had penetrated the tibial cortex and thus lifted the periosteum, new bone formed around the protruding tip of the peg (Fig. 11).

\section{POST-MORTEM AND OPERATIVE FINDINGS}

It was possible to examine four uninfected knees at necropsy between 10 days and four weeks after operation. In all four knees the macroscopic appearances were the same and the tibial prosthesis was firmly attached to the tibia. Three specimens were sectioned vertically so as to separate the bone containing the pegs from the remainder of the specimen. The radiographic appearance of bone containing a peg is shown in Figure 12. The fourth specimen was cut in the sagittal plane through the pegs and the appearance of the sectioned surface is seen in Figure 13.

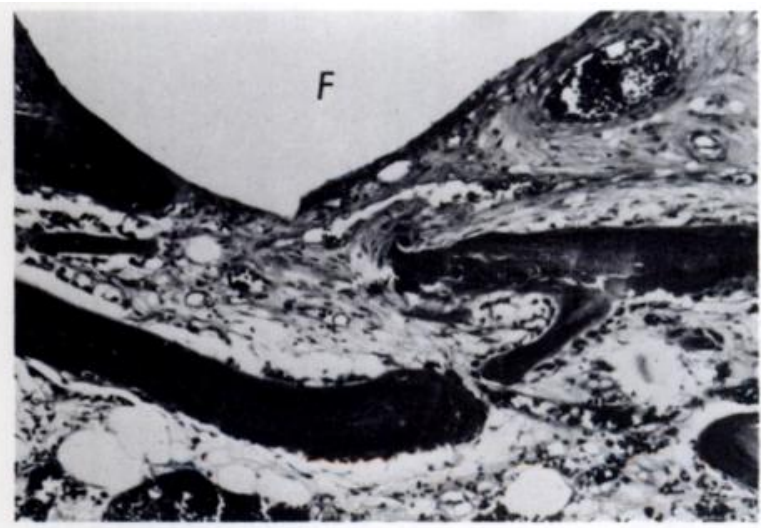

Fig. 15

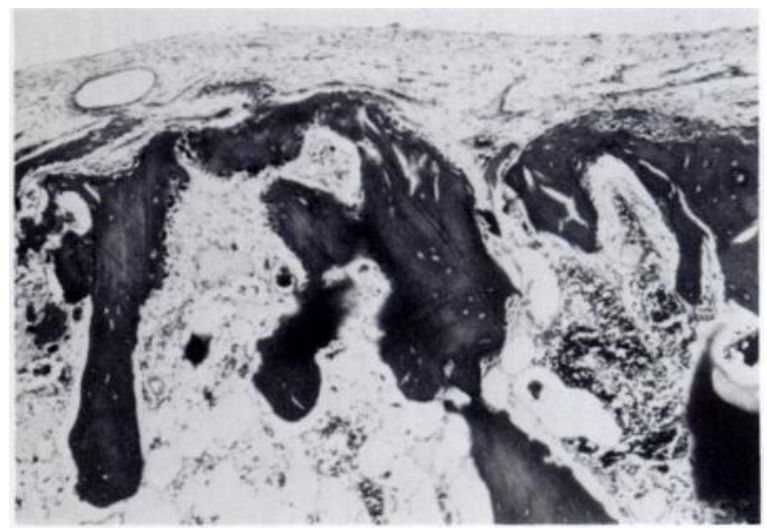

Fig. 17

Histological sections of the tissue between the flanges of a polyethylene peg used to fix the tibial component of a knee prosthesis, 10 days after operation. The position of the flanges is marked (F). Figure 14-Vascular fibrous tissue with fragments of dead bone and newly formed bone between the flanges. The area adjacent to the core of the peg is seen in the top right part of the photograph. (Haematoxylin and eosin, $\times 130$ ). Figure 15-Higher power view of tissue adjacent to a flange, showing appositional new bone formation both on living trabeculae in continuity with surrounding bone, and on fragments of dead bone. (Haematoxylin and eosin, $\times 270$ ). Figure 16 - Tissue between the flanges, with abundant new bone formation in relation to fragments of dead bone. (Haematoxylin and eosin, $\times 270$ ). Figure 17-High power view of the tibial surface immediately beneath the prosthesis, also 10 days after operation. There are fragmented vertically arranged trabeculae of dead bone in vascular fibrous tissue. There is already evidence of new bone formation at the surface of these trabeculae. (Haematoxylin and eosin, $\times 270$ ). 


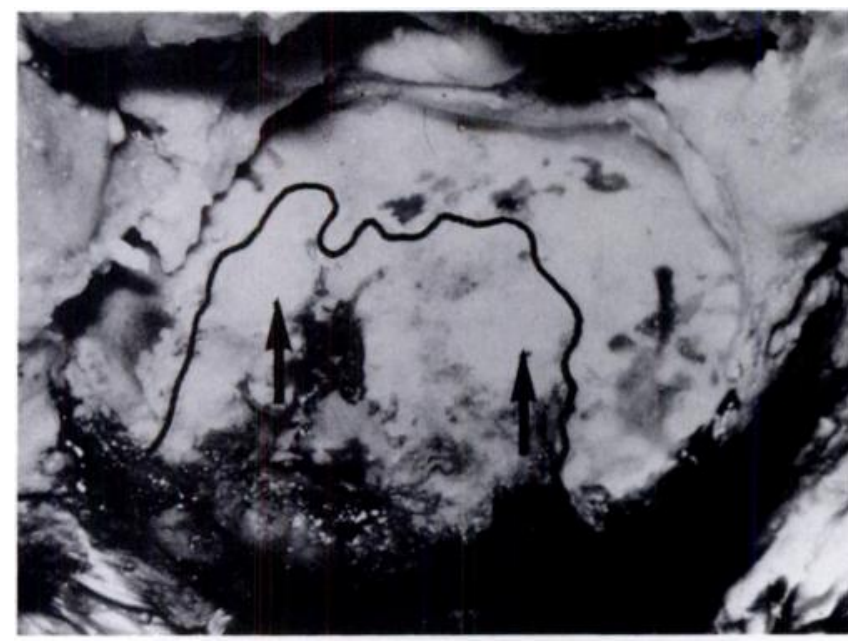

Fig. 18

Photograph of the top of the tibia 36 months after implantation of the prosthesis. The pegs had been cut by passing a reciprocating saw under the plateau of the prosthesis. The edge of the resulting area of tissue damage is outlined in black. The two pegs (arrows) merge with the white bone in which they were entombed. The remainder of the surface of the tibia where it has not been damaged by the saw consists mainly of white tissue with smaller pink areas. The histological appearances of this surface are shown in Figure 21.

The histological appearances of the bone around the polyethylene tibial component were similar in all four $k$ nees. The spaces between the flanges of the pegs were occupied at various levels by vascular granulation tissue containing fragmented bone trabeculae, by granulation tissue only, or by intact viable trabeculae in continuity with the bone surrounding the peg (Figs 14 and 15). There was new bone formation on the trabeculae adjacent to the tips of the flanges and appositional new bone formation on both fragmented dead trabeculae and the intact living trabeculae between the flanges (Fig. 16).

The area immediately adjacent to the core of the peg at the very tip of the tongue of tissue between the flanges was occupied by fibrin containing red blood cells. This region is part of the space resulting from the drill hole and new bone formation, which could only have resulted from ingrowth, was not seen within it. Beneath the polyethylene tibial plateau the fragmented ends of vertically orientated trabeculae lay in vascular fibrous tissue (Fig. 17). As in the bone around the pegs, appositional new bone was present on both living and dead fragmented trabeculae.

Two uninfected knees were revised at 10 and 36 months for patellar subluxation. At operation no movement could be detected between the tibial component and the tibial plateau in either knee. The prostheses were tightly applied to the top of the tibia and the external surface of the bone about the prosthesis appeared normal.

In the knee revised 36 months after implantation the polyethylene plateau was removed by passing the blade of a reciprocating saw between the prosthesis and the tibia to cut the root of the pegs. The appearance of the top of the tibia is shown in Figure 18. The pegs were firmly entombed in bone, and the major part of the surface of the tibia was a flat sheet of bone covered with a just-visible layer of white soft tissue. In this generally white surface there were islands of pink, filmy soft tissue below which the bone retained its original open cancellous structure. The component was one which had been made in the laboratory and had no holes on its undersurface; bone ingrowth was therefore impossible.

One peg was removed with its surrounding block of bone for histological examination. An attempt was made to withdraw the second peg with ronguers, but so firmly was the peg gripped by bone that the patient's leg could be lifted from the operating table. A screw was inserted into a drill hole in the peg. The screw and the peg were then tapped out of the tibia using an extractor. Withdrawal of the peg was

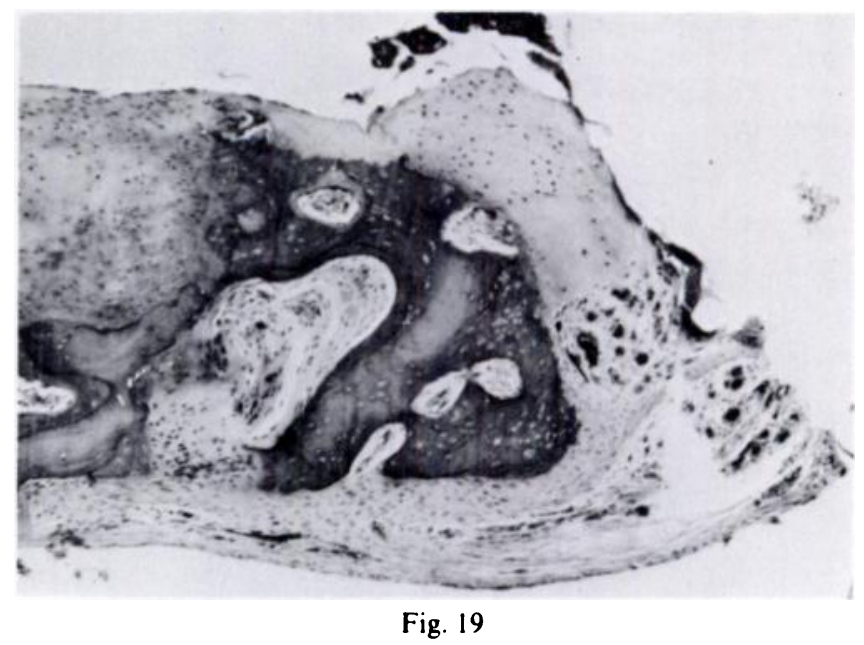

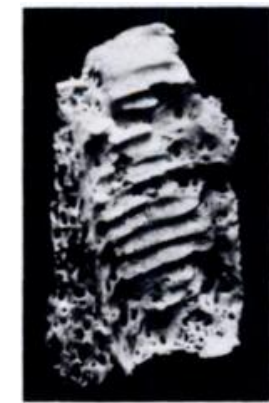

Fig. 20
Figure 19--High power view of the tissue between the flanges of a polyethylene peg, 36 months after operation, showing the presence of living bone which has formed by apposition on fragments of dead trabeculae. The upper surface of the tissue shows a layer of chondroid metaplasia which was related to the adjacent undersurface of a flange. Fibrous tissue separates polyethylene and bone on the inferior surface of the tissue. The tissue to the right is adjacent to the core of the peg and consists of vascular fibrous tissue. (Haematoxylin and eosin, $\times 300$ ). Figure 20 - Macerated specimen of the wall of a peg hole in the proximal tibia. The ridges of bone which lay between the flanges can be clearly seen. achieved by bending all its flanges. The floor of the hole was a sheet of hard bone and in its wall rings of bone could be seen and palpated.

The second knee was revised 10 months after implantation, and the tibial component was not disturbed. The outer surface of the tibia appeared normal up to its point of contact with the prosthesis. A fragment of bone was taken for histological examination from beneath the anteromedial aspect of the prosthesis.

No surface damage was visible to the naked eye on the articular surfaces of either prosthesis. The undersurface of the prosthesis in the first patient displayed its original machining marks and showed no sign of abrasive damage from the bone of the tibia.

Histological examination showed that there was living bone between the peripheral parts of the majority of the flanges but some were separated by fibrous tissue only. Only fibrous tissue lay between the flanges in the area adjacent to the peg itself, in the area corresponding to the original drill holes. The bone between the flanges formed spurs which were in continuity with the bone surrounding the peg hole (Figs 19 and 20). In some areas this bone formed a thickened plate having a cortical appearance.

Bone and polyethylene were everywhere separated by a layer of fibrous tissue. There was chondroid metaplasia in this tissue under the flanges and in the floor of the peg hole, that is in those areas where bone might have been loaded in compression. No macrophages were seen at the interface itself. In the fibrous tissue deep to the interface there were occasional collections of macrophages in relation to finely particulate high density polyethylene debris near the tips of a few flanges. The bone in the vicinity of these collections showed no evidence of resorption.

Beneath the plateau there was horizontal bridging of bone between the tips of the original, vertical trabeculae. This bone had been separated from the polyethylene by a layer of fibrous or chondroid tissue, corresponding respectively to the pink and white area as seen macroscopically. Horizontal bridging was more marked under the soft tissue displaying chondroid metaplasia, giving an appearance similar 
to a normal subchondral plate (Fig. 21). The surface of the fibrous tissue was organised into a structure resembling a synovial lining cell layer. Neither the chondroid nor the fibrous tissue contained macrophages.

A section taken from the rim of soft tissue at the margin of the tibial plateau contained macrophages and giant cells with fine intracytoplasmic polyethylene particles presumably derived from wear of the articular surface. This infiltrate did not encroach on the interface between polyethylene and bone.

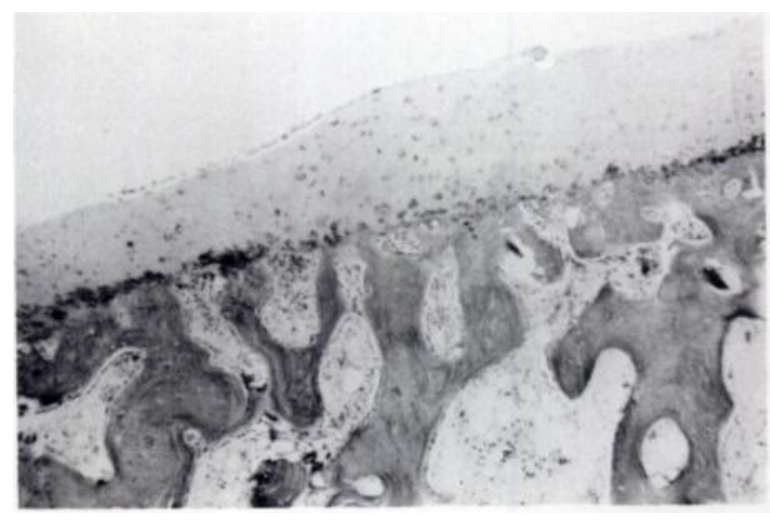

Fig. 21

High power view of the surface of the tibia beneath the prosthesis, 10 months after operation. The surface is covered by a layer of chondroid tissue and deep to this are living bone trabeculae showing horizontal bridging. Bone forming osteoblasts can be seen on the surface of trabeculae. No macrophages can be seen at the interface. (Haematoxylin and eosin, $\times 190$ ).

Infected knees. Tibial bone from beneath the polyethylene plateau and around the pegs was available from three cases revised for infection. The appearances were generally similar to those seen in the uninfected knees but small focal areas containing polyethylene debris within macrophages and giant cells were seen in the fibrous tissue at the interface between the plateau of the prosthesis and the bone. In these specimens acute and chronic inflammatory cells were present in the tissues related to the prosthesis and in the synovium but these appearances, caused by infection, were clearly distinguishable from those related to the implant itself and to the presence of polyethylene debris.

\section{DISCUSSION}

Observations in this and other studies (Freeman et al. 1981) show how the described method of fixation functions. The hole drilled in cancellous bone is intermediate in diameter between that of the tips of the flanges and that of the core of the peg. The elasticity of the flanges allows each flange to flex as it enters the bone. If a flange lies opposite an intertrabecular space when the peg comes to rest, it straightens and has living, intact trabecular bone above and below it. If the flange lies opposite intact trabeculae rather than in a space, it remains flexed, resting against the trabeculae as a barb. No bone is present between two such flanges. Not all the bone initially present between the flanges is alive; some is in the form of fractured trabecular fragments, and more bone of this kind is pressed into the wall of the hole by the drill. This bone and the living trabeculae form a scaffold upon which bone remodelling occurs within two to three weeks by a process of appositional new bone formation. Both around the peg and beneath the plateau the open spaces between transected trabeculae tend to be closed by new bone formation. The thin plate of dense bone which forms around the implant is usually visible radiologically.

Our findings suggest that although new bone forms on an existing scaffold it rarely if ever grows into areas outside the bone, and true ingrowth occurs only very rarely. Areas outside the bone are initially occupied by haematoma and finally by fibrous tissue.

Nowhere is bone in direct contact with polyethylene, the tissue at the interface being fibrous in nature. Where the prosthesis applies a compressive load to trabecular bone, such as areas in contact with the undersurface of the plateau, the peg and the flanges, this soft tissue undergoes chondroid metaplasia. The lining cell adjacent to the implant is a connective tissue cell resembling either a chondrocyte, a synoviocyte (in some areas beneath the plateau) or a fibrocyte (in some areas around the peg). The macrophage, now known to be the precursor of the osteoclast (Chambers 1980), was not seen at the interface save in relation to very occasional fragments of polyethylene debris at the tips of some flanges.

Symptomatically and mechanically the cementless method of fixation used in this study gave results as good as the method of fixation in which a layer of PMMA was interposed between the same prosthesis and bone surfaces. The radiographic appearances suggest that bone at the uncemented interface is biologically stable; bone loss was never seen and if the interface changed at all with time, it showed a slight increase in radiodensity at the bony surface.

It is recognised that the time between operation and review in this study is short by the conventions of joint replacement work. It is not claimed that the new method of fixation will function in the long term. On the other hand this is the only study of which we are aware in which a direct comparison has been made between cemented and cementless fixation of a particular prosthetic component when all other elements of the arthroplasty and the prosthesis were comparable between the groups studied. It is also believed to be the only study in which a polyethylene component has been directly bonded to bone and the results reported. An interface of this kind has been used clinically at the acetabulum by Morscher, Bombelli and Mathys (personal communication) but so far as we are aware a formal description of their results is not yet available. Although this study reports only short-term results, we believe that it is not without interest for these reasons.

This study demonstrates that a polyethylene implant can be fixed directly to cancellous bone without the intervention of cement. This conclusion applies only to the specific prosthesis and postoperative period under study; extrapolation to other implants and longer time periods may not be justified. The clinical results, the normal and unchanging radiological appearance of the 
bone at the interface, and the virtual absence of believe that this method may provide secure long-term osteoclastic cells at the interface itself, encourage us to fixation.

\section{REFERENCES}

Bargren JH, Day WH, Freeman MAR, Swanson SAV. Mechanical tests on the tibial components of non-hinged knee prostheses. J Bone Joint Surg $[\mathrm{Br}] 1978 ; 60-\mathrm{B}: 256-61$.

Bargren JH, Freeman MAR, Swanson SAV, Todd RC. ICLH (Freeman/Swanson) arthroplasty in the treatment of arthritic knee. Clin Orthop $1976 ; 120: 65-75$.

Chambers TJ. The cellular basis of bone resorption. Clin Orthop 1980;151:283-93.

Charnley J. Low friction arthroplasty of the hip: theory and practice. Berlin: Springer-Verlag, 1979.

Charnley J, Crawford WJ. Histology of bone in contact with self-curing acrylic cement. J Bone Joint Surg [Br] 1968:50-B:228.

Charnley J, Follacci FM, Hammond BT. The long-term reaction of bone to self-curing acrylic cement. J Bone Joint Surg [Br] 1968;50-B:822-9.

Chenger J, Schachar N, MacDonald D, Lewkonia R. The effect of polymethylmethacrylate on white blood cell function in vivo and in vitro. Trans Orthop Res Soc 1981:6:327.

Feith R, Sloof TJJH, Kazem I, van Rens ThJG. Strontium ${ }^{87 \mathrm{~m}} \mathrm{Sr}$ bone scanning for the evaluation of total hip replacement. J Bone Joint Surg [Br] 1976;58-B: $79-83$

Freeman MAR, Blaha JD, Brown G, Day WH, Insler HP, Revell PA. Cementless fixation of a tibial component for the knee. Trans Orthop Res Soc $1981 ; 6: 157$.

Freeman MAR, Todd RC, Bamert P, Day WH. ICLH arthroplasty of the knee: 1968-1977. J Bone Joint Surg [Br] 1978;60-B:339-44.

Goldberg VM, Henderson BT. The Freeman-Swanson ICLH total knee arthroplasty: complications and problems. J Bone Joint Surg [Am] 1980:62-A:1338-44.

Insall JN, Ranawat CS, Aglietti P, Shine J. A comparison of four models of total knee-replacement prostheses. J Bone Joint Surg [Am] 1976; 58-A :754-65.

Petty W. The effect of methylmethacrylate on bacterial phagocytosis and killing by human polymorphonuclear leukocytes. J Bone Joint Surg [ Am] 1978;60-A:752-7.

Petty W, Bryan RS, Coventry MB, Peterson LFA. Infection after total knee arthroplasty. Orthop Clin North Am 1975;6:1005-14.

Sauer BW, Lade RB, Mercer HA. Biomechanical evaluation of porous high density polyethylene coated canine femoral head prostheses. Trans Orthop Res Soc 1980:5:315

Sauer BW, Lade RB, Mercer HA. Long-term stabilisation of canine femoral head prostheses using porous high density polyethylene coatings. Trans Orthop Res Soc 1981;6:173.

Sauer BW, Weinstein AM, Klawitter JJ, Hulbert SF, Leonard RB, Bagwell JG. The role of porous polymeric materials in prosthesis attachment. J Biomed Mater Res 1974;8 (5th symposium): 145-53.

Skolnick MD, Bryan RS, Peterson LFA, Combs JJ Jr, Ilstrup DM. Polycentric total knee arthroplasty: a two-year follow-up study. J Bone Joint Surg [Am] 1976:58-A:743-8.

Skolnick MD, Coventry MB, Ilstrup DM. Geometric total knee arthroplasty: a two-year follow-up study. J Bone Joint Surg [Am] 1976;58-A : 749-53.

Swanson SAV. Mechanical aspects of fixation. In: Swanson SAV, Freeman MAR, eds. The scientific basis of joint replacement. Tonbridge Wells: Pitman Medical Publishing Company, 1977: 130-57.

Willert H-G, Ludwig J, Semlitsch M. Reaction of bone to methacrylate after hip arthroplasty. J Bone Joint Surg [Am] 1974;56-A : 1368-82. 